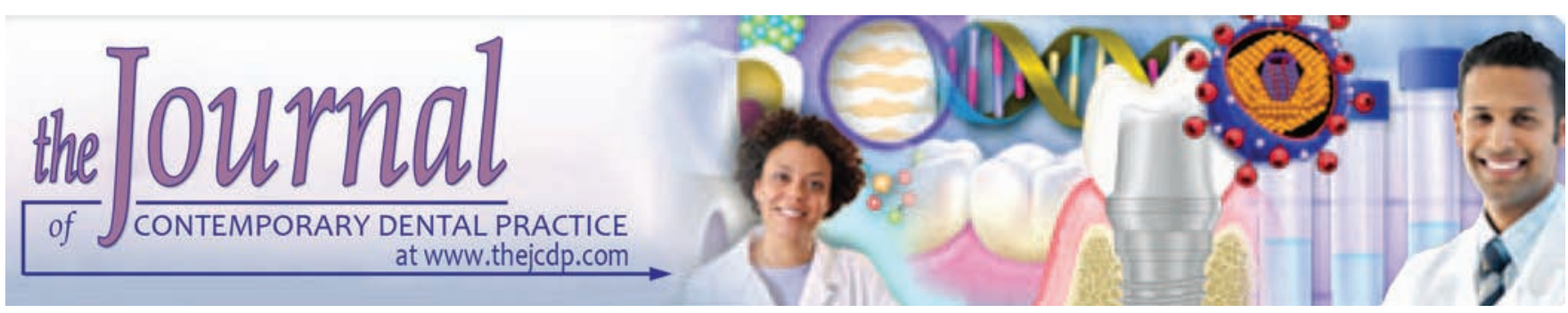

\title{
Mechanical and Physical Properties of Two Different Resin-based Materials: A Comparative Study
}

\author{
${ }^{1}$ Hosam Baeshen, ${ }^{2}$ Basem N Alturki, ${ }^{3}$ Wjoud W Albishi, ${ }^{4}$ Fahad M Alsadi, ${ }^{5}$ Khaled M El-Tubaigy
}

\begin{abstract}
Aim: The purpose of this study was to evaluate the degree of conversion (DC) of two different resin-based composite materials (nanofill composite and ormocer) and correlate it with some mechanical properties of these two restorative materials.

Materials and methods: Two different resin-based materials (Filtek Supreme XT and Admira) were tested. A total of 30 samples of each type of selected composite were prepared. Specimens were immersed in distilled water for 24 hours. Then, the specimens were subjected to DC, hardness, and diametral tensile strength (DTS) measurements. The data obtained were tabulated for statistical analysis. The $t$-test was used to detect the significant difference among the variables tested in this study. Furthermore, the interrelationship between the studied parameters was investigated using a simple correlation coefficient statistical test.
\end{abstract}

Results: Statistically significant differences were observed regarding DC, hardness, and DTS. Filtek Supreme XT presented the highest values. There was a positive correlation between DC and hardness. Also there was a correlation between DC and DTS, but it was not significant.

Conclusion: Under the tested experimental conditions, the DC of Filtek Supreme XT was higher than that of ormocer.

\footnotetext{
${ }^{1}$ Department of Orthodontics, Faculty of Dentistry, King Abdulaziz University, Jeddah, Kingdom of Saudi Arabia Al-Farabi Dental School, Jeddah, Kingdom of Saudi Arabia

${ }^{2}$ Al-Farabi Dental School, Jeddah, Kingdom of Saudi Arabia Dental Research Lab, Faculty of Dentistry, King Abdulaziz University, Jeddah, Kingdom of Saudi Arabia

${ }^{3} \mathrm{Al}$-Farabi Dental School, Jeddah, Kingdom of Saudi Arabia

${ }^{4}$ Dental Research Lab, Faculty of Dentistry, King Abdulaziz University, Jeddah, Kingdom of Saudi Arabia

${ }^{5}$ Department of Restorative Dental Science, Al-Farabi Dental Colleges, Jeddah, Kingdom of Saudi Arabia

Corresponding Author: Hosam Baeshen, Department of Orthodontics, Faculty of Dentistry, King Abdulaziz University Jeddah, Kingdom of Saudi Arabia, Phone: +96626403443 e-mail: habaeshen@kau.edu.sa
}

Accordingly, Filtek Supreme XT showed better mechanical properties.

Clinical significance: Filtek Supreme XT showed superior mechanical properties. Therefore, orthodontic bracket-based composite combinations may also be expected to perform well clinically over the lifetime of a bonded orthodontic appliance.

Keywords: Admira, Degree of conversion, Diametral tensile strength, Hardness, Nanofilled composite.

How to cite this article: Baeshen $\mathrm{H}$, Alturki BN, Albishi WW, Alsadi FM, El-Tubaigy KM. Mechanical and Physical Properties of Two Different Resin-based Materials: A Comparative Study. J Contemp Dent Pract 2017;18(10):905-910.

Source of support: Nil

Conflict of interest: None

\section{INTRODUCTION}

During the past 20 years, dental composites have become popular as filling materials for anterior and posterior teeth as well as for bonding orthodontic brackets to teeth. This is due to the material's ability to match tooth color, withstand oral fluids, and bind to acid-etched enamel surface. However, these materials also possess some drawbacks. ${ }^{1,2}$ One of the most important shortcomings of dental composites is their degradation, which leads to reduced mechanical and esthetic properties. In addition, some of the released components are sensitive/irritative agents. ${ }^{3-5}$ Degradation of dental composites occurs as a result of incomplete polymerization and influence of oral fluids, which will lead to resin wear, filler exposure, and then filler loss. Consequently, the amount of degradation depends on the degree of cross-linking in the polymerized matrix and the environmental impact. ${ }^{6-8}$

Some laboratory studies have shown that an increase in volume of filler increases the wear resistance of dental composite besides, thereby increasing the strength and hardness. Other investigators suggest certain improvements in composite restorative materials to improve 
their durability by increasing degree of cure of the matrix polymer, which will inhibit diffusion of penetration. Furthermore, additional cross-linking will reduce swelling and damage by solvent. ${ }^{9-11}$

From a clinical point of view, surface microhardness and strength of restorative materials are important properties. Accordingly, studies on posterior composites introduced packable composites, which showed better physical and mechanical properties and additional improvement in handling than amalgam restoration. Ormocer (organically modified ceramics) is one of the packable composites, which uses a novel resin system inorganic-organic copolymer in its formulation that allows modifications of its mechanical parameters. ${ }^{12,13}$

Recently, new modern types of composites have been developed which are nanofilled composites. This type of composite differs from others by utilizing nanosized filler particles rather than the microsized ones. The size of the new filler system is below the wavelength of the curing visible light. Therefore, these fillers do not scatter or absorb the light and provide radiopacity without interfering with the material's esthetics. Besides, this type has high filler loading, which increases strength and hardness of the composite. ${ }^{14,15}$ Based on the proceedings, we are targeting to evaluate the degree of conversion (DC) of two different resin-based composite materials and correlate it with some mechanical properties of these two restorative materials.

\section{MATERIALS AND METHODS}

- Ormocer esthetic restorative material (admira)

- Nanofilled esthetic restorative material (Filtek Supreme XT).

Details of the materials tested with their compositions are given in Table 1.

\section{Preparation of Samples}

A total of 10 samples of each type of selected composite resin materials were cured according to the manufacturer,s instructions. Then, the specimens were tested for their DC.

\section{Evaluation of Degree of Conversion}

The percentage of the DC was calculated for both the cured and the uncured conditions of the two composite resins tested. This was performed using the Fourier transform infrared (FTIR) spectroscopy (Bruker FTIR spectroscopy, Vector 22, Germany). ${ }^{16,17}$

\section{Degree of Conversion for the Uncured Composite Resin}

The uncured composite resin pastes (ormocer and Filtek Supreme) were smeared on potassium bromide (KBr) disks, one for each paste. The absorbance peaks of infrared rays by the aliphatic Cs of the two composite resins were tested. This was performed using FTIR as shown in Graphs 1, and 2. The frequency of the infrared region used was between 4000 and $500 \mathrm{~cm}^{-1}$ wave number. The resolution was $4 \mathrm{~cm}^{-1}$. The infrared absorbance mode by the specimen was recorded.

\section{Degree of Conversion for the Cured Composite Resin}

In the case of the cured composite resin materials, the DC was obtained through the following steps. Small amount of each composite resin paste was placed in stainless steel mold (10 mm diameter and $1 \mathrm{~mm}$ in thickness); vaseline was used as a lubricant for easy separation of the specimen. The composite paste was covered by two translucent polyethylene strips on both surfaces. The paste with the strips was compressed between two glass slides to remove the excess and form a thin film of the paste. The specimen was cured using a visible blue light source (Spring Health Products, USA). The specimen was cured for 30 seconds from the top and for 10 seconds from the bottom according to the manufacturer's instructions (the whole curing time was 40 seconds for each specimen). Immediately after curing, the specimen was removed and immersed

Table 1: Materials used in this study

\begin{tabular}{|c|c|c|c|c|}
\hline Material & Trade name & Composition & Batch/Lot no. & Manufacturer \\
\hline Ormocer & Admira & $\begin{array}{l}\text { Ormocer resin } \\
\text { Dimethacrylates (Bis-GMA, UDMA, and TEGDMA) } \\
\text { Camphorquinone and amines } \\
\text { Butylhydroxytoluene } \\
\text { Inorganic glass fillers }(0.7 \mu \mathrm{m}) \\
\text { Filler content: } 78.5 \mathrm{wt} \%\end{array}$ & $\begin{array}{l}550898 \\
\text { Color shade } \\
\text { A3 }\end{array}$ & $\begin{array}{l}\text { Voco Gmbh, Cuxhaven, } \\
\text { Germany }\end{array}$ \\
\hline $\begin{array}{l}\text { Nanofilled } \\
\text { composite }\end{array}$ & Filtek-Supreme-XT & $\begin{array}{l}\text { Monomer matrix contains Bis-GMA, UDMA, } \\
\text { triethylene, glycol dimethacrylate, and Bis-EMA resin } \\
\text { Inorganic filler particles ( } 78 \mathrm{wt} \%), 40 \mathrm{~nm}^{-1} \mu \mathrm{m} \text { ) are a } \\
\text { combination of aggregated zirconia/silica cluster and } \\
\text { a non agglomerated/nonaggregated silica filler }\end{array}$ & $\begin{array}{l}3910 \\
\text { Color shade } \\
\text { A3 }\end{array}$ & $\begin{array}{l}\text { 3M ESPE Dental } \\
\text { Products, St. Paul, MN } \\
55144\end{array}$ \\
\hline
\end{tabular}

Bis-EMA: ethoxylated bisphenol-A dimethacrylate 

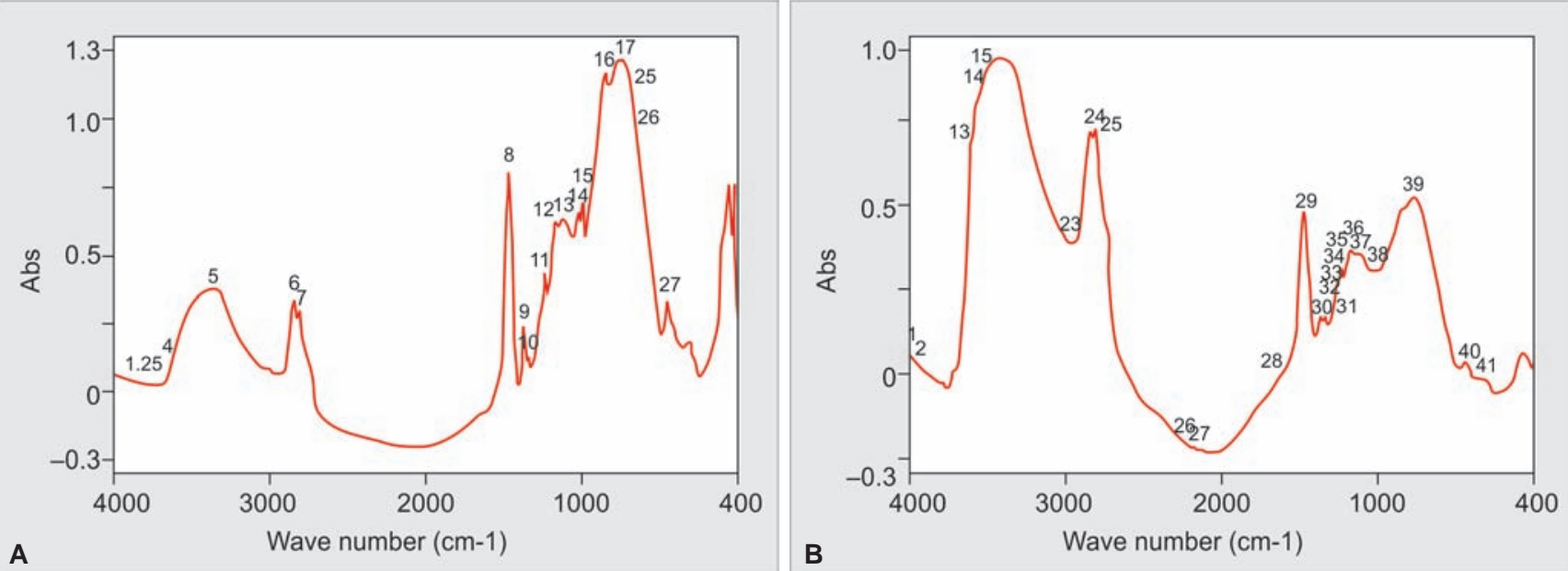

Graphs 1A and B: (A) Uncured sample and (B) cured sample of ormocer restorative material
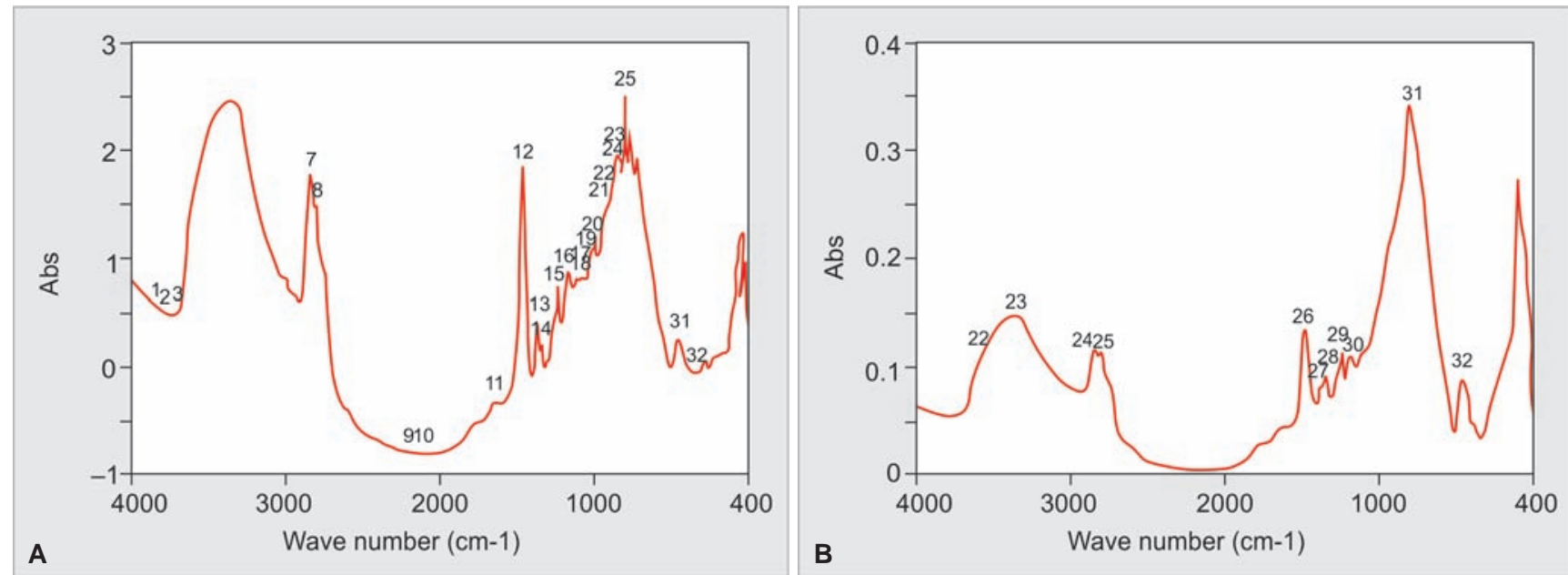

Graphs 2A and B: (A) Uncured sample and (B) cured sample of nanofilled restorative material

in distilled water at $23^{\circ} \mathrm{C} \pm 1$ for 24 hours. Ten cured specimens and one uncured resin were prepared for each type. The total number was 20 cured and two uncured specimens in each type of composite tested.

After storage, each specimen was pulverized into a fine powder using a mortar and pestle. Fifty micrograms of the ground powder was mixed with $\mathrm{KBr}$ spectroscopic grade (as a background) in an amount that is 10 times of the specimen powder. Both powders were then compressed into a disk form. The compressed disk was irradiated by the infrared spectrum of the FTIR spectroscopy. The absorbance peaks of infrared rays causing stretching vibration of the aliphatic $\mathrm{C}=\mathrm{C}$ double bonds (at $1632-1637 \mathrm{~cm}^{-1}$ ) and of the aromatic C...C double bonds, which are used as internal reference (at 1610$1620 \mathrm{~cm}^{-1}$ ), were recorded (Graphs $1 \mathrm{~A}$ and $\left.2 \mathrm{~A}\right) .{ }^{16,17}$ The percentage of $\mathrm{DC}$ for each specimen was calculated from the following equation:

$$
\mathrm{DC} \%=\left[1-\frac{(\mathrm{C}=\mathrm{C} / \mathrm{C} \ldots \mathrm{C}) \text { after curing }}{(\mathrm{C}=\mathrm{C} / \mathrm{C} \ldots \mathrm{C}) \text { before curing }}\right] \times 100
$$

\section{Evaluation of Surface Hardness}

\section{Preparation of the Samples}

A total of 10 disk-shaped samples of each selected restorative material were fabricated in a Teflon mold, $8 \mathrm{~mm}$ length $\times 4 \mathrm{~mm}$ width $\times 2 \mathrm{~mm}$ thickness, as described previously (Fig. 1A). ${ }^{18}$ The specimens were light-cured from the top and the bottom for 40 seconds according to the manufacturer's instructions. After curing, the specimens were removed from the mold and immersed in distilled water at $37^{\circ} \mathrm{C}$ for 24 hours. The specimens were then fixed in acrylic resin boxes with exposed surface. ${ }^{18-20}$

\section{Measuring of Surface Hardness}

The surface hardness testing was accomplished using Vickers microhardness tester (digital Vickers microhardness testers, FM-7, Japan) (Fig. 1B) at room temperature $\left(18 \pm 2^{\circ} \mathrm{C}\right)$. The disk-shaped specimens in the acrylic boxes were fixed on the tester's holder and 

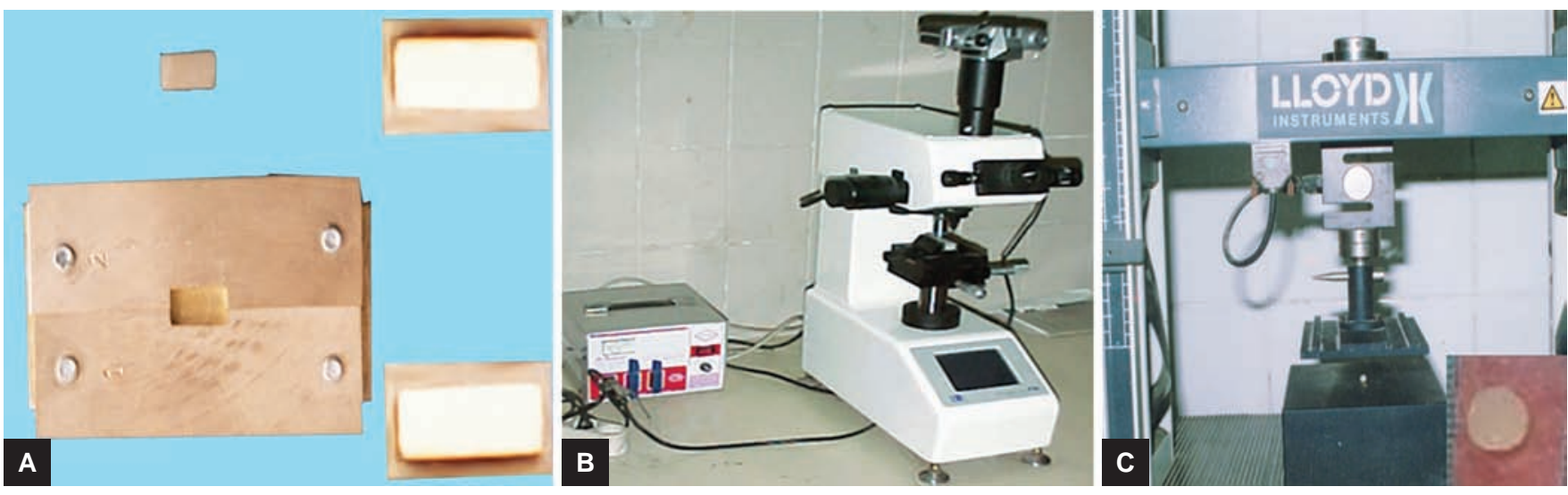

Figs 1A to C: (A) Composite specimens for hardness test; $(B)$ hardness tester; and (C) universal testing machine with specimen for DTS test

adjusted under the microscope. The Vickers diamond tip was used to make five indentations on each sample's surface. About 50 gm standardized force was applied for 5 seconds. This standard force was chosen after several trials of applying different loads; this load was sufficiently small to suppress any tendency to cracking, which can grossly affect the hardness measurement. The indentation was measured digitally in terms of Vickers hardness number (VHN) according to the following equation $^{21}$ :

$\mathrm{VHN}=1854.4 \times \mathrm{P} / \mathrm{d}^{2}$

where $\mathrm{P}$ is the applied indentation load,

$\mathrm{d}$ is the area of indentation.

\section{Evaluation of Diametral Tensile Strength}

\section{Preparation of the Samples}

A total number of 10 disc-shaped specimens of each selected restorative material $(6 \mathrm{~mm} \times 3 \mathrm{~mm})$ (Fig. 1C) were prepared and stored in distilled water at $23^{\circ} \mathrm{C} \pm 1$ for 24 hours as described previously. ${ }^{20,22}$

\section{Measurement of the Diametral Tensile Strength}

Immediately before testing, the specimen thickness and diameter were measured using a caliber. The diametral tensile strength (DTS) test was performed on a universal testing machine (Lloyed, Type 500, England) (Fig. 1C). The specimens were compressed between two diametrically opposite generators of its surfaces to produce a biaxial stress distribution within the specimen. The specimens were subjected to a compression load at a cross-head speed of $0.5 \mathrm{~mm} /$ minute until a fracture occurs. The maximum tensile stress, which act across the loaded diameter, was calculated according to the following equation $^{21,23}$ :

$\sigma:=2 \mathrm{P} / \pi \mathrm{DT}$

where $\sigma=$ maximum tensile strength,
$\mathrm{P}=$ the applied load,

$\mathrm{D}=$ specimen's diameter.

\section{Statistical Analysis}

All data were analyzed using t-test. The interrelationship between the studied properties was investigated using a simple correlation coefficient statistical test.

\section{RESULTS}

\section{Degree of Conversion}

Table 2 shows that the mean DC\% and standard deviation (SD) for ormocer and nanofilled restorative materials were $47.98 \pm 0.69$ and $58.24 \pm 0.96$ respectively. $t$-Test showed that there was very high significant difference $(\mathrm{p}<0.001)$ between mean DC\% of both ormocer and nanofilled restorative materials. The ormocer and nanofilled restorative materials (uncured and cured) were obtained using FTIR (Graph 1) for ormocer and (Graph 2) for nanofilledrestorative materials.

\section{Hardness}

Table 2 shows that by comparison between the hardness values of both ormocer and nanofilled restorative materials, there was very high significant difference. The hardness values for nanofilled restorative materials are higher than that for ormocer restorative materials.

Table 2: Comparison between mean \pm SD of DC, hardness, and DTS of ormocer and nanofill restorative material

\begin{tabular}{|c|c|c|c|c|}
\hline \multirow[b]{2}{*}{ Property } & \multicolumn{2}{|c|}{ Mean $\pm S D$} & \multirow[b]{2}{*}{ t-value } & \multirow[b]{2}{*}{$p$-value } \\
\hline & Nanofilled & Ormocer & & \\
\hline DC & $58.24 \pm 0.96$ & $47.98 \pm 0.69$ & 25 & $<0.001^{* \star *}$ \\
\hline Hardness & $98.57 \pm 5.22$ & $71.11 \pm 2.34$ & 17.2 & $<0.001^{\star \star *}$ \\
\hline DTS & $35.24 \pm 0.71$ & $33.86 \pm 0.0 .59$ & 8.6 & $<0.001^{* * *}$ \\
\hline
\end{tabular}


Mechanical and Physical Properties of Two Different Resin-based Materials

Table 3: Correlation between DC and properties

\begin{tabular}{llll}
\hline & $D C$ & Hardness & DTS \\
\hline DC & 1 & 0.145 & 0.201 \\
$\mathrm{p}$ & & 0.689 & 0.57 \\
\hline
\end{tabular}

Correlation is significant at $p \leq 0.05$

\section{Diametral Tensile Strength}

Table 2 shows that by comparison between the DTS values of both ormocer and nanofilled restorative materials, there was very high significant difference. The DTS values for nanofilled restorative material are higher than that of ormocer restorative material.

\section{Correlation between DC and Properties}

Table 3 shows that there was positive correlation between DC and hardness. Also there was correlation between DC and DTS, but it was not significant.

\section{DISCUSSION}

During the past 20 years, dental composites have become popular as filling materials for anterior and posterior teeth. This is due to the material's ability to match tooth color, withstand oral fluid, and bind to acid-etched enamel surface. Moreover, composite materials are considered an integral armamentarium for bonding orthodontic brackets to teeth. ${ }^{23}$ The esthetic restorative materials used in this study included an ormocer-based restorative material (admira) and nanofilled composite. A different matrix system in ormocer resins was developed. The ormocer is organically modified ceramics, and this class of material represents a novel inorganic-organic copolymer in the formulation that allows for modification of its mechanical parameters. ${ }^{24,25}$ Recently, new modern types of composites have been developed, which are nanofilled composites. This type has been produced with nanofiller technology, which reduces the interstitial spacing of the filler particles and, therefore, provides increased filler loading and better physical and mechanical properties. ${ }^{9,26,27}$

The immersion in distilled water was done as test specification to prevent specimen desiccation and allow for composite to postcure if any occurs. The 24 hours storage period before the test was essential for elution of unreacted component from the composite. This immersion was done under $37^{\circ} \mathrm{C}$ to simulate temperature of oral mouth. ${ }^{28}$

\section{Degree of Conversion}

The DC was measured using the FTIR. The FTIR has proven to be a powerful technique and a reliable method. It measures the total amount of the unpolymerized groups in the polymer directly before and after curing of composite resin materials. Adequate polymerization is a critical factor in obtaining optimal physical performance of composite material and is related to better clinical performance. There are many variables that affect degree of cure, which are filler particle size, distribution and loading, and also the resin matrix. ${ }^{29}$

From the results, it is clear that the DC of nanofilled restorative material (Filtek Supreme XT) is higher than that of ormocer restorative material (admira). This may be attributed to the Filtek Supreme XT utilizing nanofiller particles $(5-20 \mathrm{~nm})$, which are below wavelength of the curing visible light. Hence, they do not scatter the light and, thus, enhance better light transmission and ensure proper curing. Moreover, Filtek Supreme XT matrix replaced most of the bisphenol A glycol dimethacrylate resin matrix with urethane dimethacrylate (UDMA) and triethyleneglycol DMA(TEGDMA), and bisphenol-ethoxylate. The UDMA and TEGDMA are flexible monomers, which was proven to enhance the DC. ${ }^{30}$

Moreover, some investigators compare the $\mathrm{DC}$ and selected mechanical properties of ormocer with dimethacrylate mixture-based composite. They found that there was significantly lower double bond conversion of ormocer. This is due to the ormocer being a highly functionalized compound. Moreover, it is known that in photopolymerization, a higher degree of functionality (greater number of double bond per molecule) leads to denser network. In a denser network, the double bonds are less accessible to polymerization. This significantly reduces the extent of double bond conversion, leaving a large portion of double bonds unreacted..$^{31,32}$

\section{Hardness}

Composite hardness results from the interaction of multiple factors associated with the resin matrix and the filler particles. Final hardness depends on both the composition and the degree of polymerization of the resin matrix. Hardness has often been used as an index of the ability of material to resist abrasion. Besides, the ormocer utilizes barium glass fillers, which have lower hardness than zirconia fillers utilized in Filtek Supreme restorative material. ${ }^{33}$

\section{Diametral Tensile Strength}

The behavior of brittle materials was evaluated by DTS test. The brittle material rarely fails under compression, so testing its tensile properties is more beneficial for its clinical performance. The DTS test was performed on a universal testing machine, which is a reliable and accurate method..$^{21}$ The results of this study are in agreement with another study in which the higher DC percentage led to a greater strength of the material. ${ }^{20,34}$ 


\section{CONCLUSION}

Under tested experimental conditions, the DC of Filtek Supreme XT was higher than that of ormocer. Accordingly, Filtek SupremeXT showed superior mechanical properties. Therefore, orthodontics bracket base-composite combinations may also be expected to perform well clinically over the lifetime of a bonded orthodontic appliance. Considering the results of this study and Bishara et $\mathrm{al}^{35}$ and Chalipa et $\mathrm{al}^{36}$ study, successful application of nanocomposites can be recommended for bonding orthodontic brackets.

\section{REFERENCES}

1. Phillips RW, Avery DR, Mehra R, Swartz ML, McCune RJ. Observations on a composite resin for Class II restorations: three-year report. J Prosthet Dent 1973 Dec;30(6):891-897.

2. Leinfelder KL, Sluder TB, Santos JF, Wall JT. Five-year clinical evaluation of anterior and posterior restorations of composite resin. Oper Dent 1980;5:57-65.

3. Oysaed H, Ruyter IE. Water sorption and filler characteristics of composites for use in posterior teeth. J Dent Res 1986 Nov;65(11):1315-1318.

4. Inoue K, Hayashi I. Residual monomer (Bis-GMA) of composite resins. J Oral Rehabil 1982 Nov;9(6):493-497.

5. Lee SY, Greener EH, Menis DL. Detection of leached moieties from dental composites in fluids simulating food and saliva. Dent Mater 1995 Nov;11(6):348-353.

6. Geurtsen W. Substances released from dental resin composites and glass ionomer cements. Eur J Oral Sci 1998 Apr;106(2 Pt 2): 687-695.

7. Ruyter LE. Physical and chemical aspects related to substances released from polymer materials in aqueous environment. Adv Dent Res 1995 Dec;9(4):344-346.

8. Ferracane JL. Elution of leachable components from composites. J Oral Rehabil 1994 Jul;21(4):441-452.

9. Craig RG, Powers JM. Wear of dental tissues and materials. Int Dent J 1976 Jun;26(2):121-133.

10. Prasad SV, Calvert PD. Abrasive wear of particle-filled polymer. J Mater Sci 1980;15:1746-1754.

11. McKinney JE, Wu W. Chemical softening and wear of dental composites. J Dent Res 1985 Nov;64(11):1326-1331.

12. Manhart J, Kunzelmann KH, Chen HY. Mechanical properties and wear behavior of light-cured packable composite resins. Dent Mater J 2000 Jan;16(1):33-40.

13. Mair LH, Stolarski TA, Vowles RW, Lloyd CH. Wear: mechanisms, manifestations and measurement. Report of a workshop. J Dent 1996 Jan-Mar;24(1-2):141-148.

14. 3M ESPE Dental Product. Filtek Supreme plus universal restorative a true nano-composite. 3M brochure 2005.

15. Mitra SB, Wu D, Holmes BN. An application of nanotechnology in advanced dental materials. J Am Dent Assoc 2003 Oct;134(10):1382-1390.

16. Turssi CP, Ferracane JL, Vogel K. Filler features and their effects on wear and degree of conversion of particulate dental resin composites. Biomaterials 2005 Aug;26(24):4932-4937.

17. Silikas N, Eliades G, Watts DC. Light intensity effects on resin-composite degree of conversion and shrinkage strain. Dent Mater 2000 Jul;16(4):292-296.

18. Yap AU, Lye KW, Sau CW. Surface characteristics of tooth colored restoration polished utilizing different polishing systems. Oper Dent 1997 Nov-Dec;22(6):260-265.
19. Gordan VV, Patel SB, Barrett AA, Shen C. Effect of surface finishing and storage media on bi-axial flexure strength and microhardness of resin-based composite. Oper Dent 2003 Sep-Oct;28(5):560-567.

20. Aguiar FH, Braceiro AT, Ambrosano GM, Lovadino JR. Hardness and diametral tensile strength of a hybrid composite resin polymerized with different modes and immersed in ethanol or distilled water media. Dent Mater 2005 Dec;21(12):1098-1103.

21. Anusavice KJ. Phillips' science of dental materials. 11th ed. Philadelphia: W.B. Saunders Company; 2003. p. 400-410.

22. Chung KH. The relationship between composition and properties of posterior resin composites. J Dent Res 1990 Mar;69(3):852-856.

23. Keim RG, Gottlieb EL, Nelson AH, Vogels DS 3rd. 2002 JCO study of orthodontic diagnosis and treatment procedures. Part 1. Results and trends. J Clin Orthod 2002 Oct;36(10): 553-568.

24. Craig RG, Powers JM. Restorative dental materials. 11th ed. St. Louis: Mosby Year Book; 2002. p. 232-240.

25. Theodore MR, Harald OH, Edward JR. Art and science of operative dentistry. 4th ed. St. Lois: Mosby Company; 2002. p. 471-499.

26. O'Brien WJ. Polymeric restorative materials. In: Composite and sealants in dental materials and their selection. 3rd ed. Chicago, Quintessence Publishing Company; 2002. p. 113-131.

27. Mohanbabu V, Mala K, Priyadharshini IK. The importance of dentin collagen fibrils on the marginal sealing of adhesive restorations: an in vitro study. Int Dent Med J Adv Res 2015;1:1-5.

28. Ferracane JL, Marker VA. Solvent degradation and reduced fracture toughness in aged composites. J Dent Res 1992 Jan;71(1):13-19.

29. Imazato S, Tarumi H, Kobayashi K, Hiraguri H, Oda K, Tsuchitani Y. Relationship between the degree of conversion and internal discoloration of light-activated composite. Dent Mater J 1995 Jun;14(1):23-30.

30. dos Santos GB, Alto RV, Filho HR, da Silva EM, Fellows CE. Light transmission on dental resin composites. Dent Mater 2008 May;24(5):571-576.

31. Raphael RP, Poskus LT, Silva EM. Depth of cure of dental composites submitted to different light curing modes. J Appl Oral Sci 2006 Apr;14(2):71-76.

32. Moszner N, Gianasimidis A, Klapdohrn S, Fischer UK, Rheinberger V. Sol-gel materials 2. Light curing dental composites based on ormocers of crosslinking alkoxysilanes methacrylates and further nano-components. Dent Mater 2008 Jun;24(6):851-857.

33. Alonso RCB, Cunha LG, Correr GM, Santos PH, Sinhoreti MAC. Comparative evaluation of Knoop hardness and depth of cure of ORMOCER based resin composite. Cienc Odontol Bras 2004;7(1):6-13.

34. Asmussen E, Peutzfeldt A. Influence of UEDMA BisGMA and TEGDMA on selected mechanical properties of experimental resin composites. Dent Mater 1998 Jan;14(1):51-56.

35. Bishara SE, Ajlouni R, Soliman MM, Oonsombat C, Laffoon JF, Warren J. Evaluation of a new nano-filled restorative material for bonding orthodontic brackets. World J Orthod 2007 Spring;8(1):8-12.

36. Chalipa J, Akhondi MS, Arab S, Kharrazifard MJ, Ahmadyar M. Evaluation of shear bond strength of orthodontic brackets bonded with nano-filled composites. J Dent (Tehran) 2013 Sep;10(5):461-465. 